\section{A BLOOD REACTION IN DIABETES MELLITUS; ITS CAUSE AND DIAGNOSTIC VALUE.}

By R. T. WILLIAMSON, M.D., F.R.C.P. LOND., PHYsiclai to The axcoats Hospital, MaNChRSTER, aNd assistay LRCTURER OX MEDICINE AT OWENS COLLEGE.

IN 1896 I recorded ${ }^{1}$ a reaction which $I$ believe to be peculiar to the blood of patients suffering from diabetes mellitus. A drop of blood taken from the finger of a diabetic patient decolourises a warm alkaline solution of methylene blue, when mixed in certain proportions, whilst blood from healthy persons or from individuals suffering from other diseases has no such action when mixed in the same proportion. The reaction is due to the greater reducing power of diabetic blood and is obtained as follows. At the bsttom of a small, narrow test-tube is placed a drop of water -40 cubic millimetres. To this are added 20 cubio millimetres of blood taken from the finger of the diabetic patient. Then 1000 cubic millimetres (one cubic centimetre) of a watery solution of methylene blue ( 1 in 6000) and finally 40 cubic millimetres of liquor potassæ (B. P.) are added. Into a similar tube are placed 20 cubic millimetres of normal blood with the same proportions of methylene blue and liquor potassæ. The mixed fluids in each tube will have a fairly deep blue or bluish-green colour. Both small test-tubes are placed in a beaker or very large wide test-tube containing water and the water is heated and kept boiling for four minutes. At the end of this time the fluid in the small testtube containing the diabetic blood will have lost its blue colour and become dirty yellow, whilst that in the tube containing non-diabetic blood will remain blue or bluish-green. (The exact quantities of the fluid used may be measured by the small tubes supplied with the hæmocytometer and hæmoglobinometer of Gowers.)

I have examined the blood in 43 cas as of diabetes mellitus and have always obtained the reaction mentioned. I have examined the blood in 100 cases of othor diseases of the most varied forms and also the blood of healthy persons on innumerable occasions, but, when the fluids have been mixed in the proportion above stated, have never obtained the reaction. My results have been confirmed in Germany by Loe wy, ${ }^{2}$ Goldscheider, ${ }^{3}$ and R. Müller ${ }^{4}$; in France by Le Goff, ${ }^{5}$ P. Marie, Lyonnet, ${ }^{6}$ and Lépine : in Italy by Baduel and Castellani, ${ }^{7}$ Ferrannini, ${ }^{8}$ and Lucibelli ${ }^{9}$; and in America by Futscher ${ }^{10}$ (in Professor Osler's clinic). Further observations which $I$ have made indicate the cause and diagnostic value of the reaction.

CAUSE OF THE ReACTION.

1. This reaction, peculiar to diabetic blood, is evidently due to the presence of some substance in solution in the blood serum. Large quantities of blood obtained post mortem from the internal jugular vein of three cases of diabetes mellitus were allowed to stand until the serum separated on the surface and the red corpuscles sank to the bottom of the vessel. In each case the blood serum, free from red corpuscles, gave the reaction-i.e., decolourised methylene blue in the proportion given above-whilst the serum obtained in a similar manner from non-diabetic blood gave no reaction (in the proportions mentioned).

2. Blood serum from a diabetic subject loses the power of giving the reaction after it is submitted to the action of yeast. In three cases of diabetes mellitus large quantities of blood were taken post mortem from the internal jugular vein and allowed to stand for 24 hours until the serum had separated.

1 Brit. Mer. Jour., Sept. 19th, 1896.

2 Berliner Klinische Wochenschrift, 1897, No. 46, and Fortschritte der Medicin, 189

3 Deutsche Medicinische Zeitung. 1898.

4 Münchener Medicinische Wochenschrift, 1899, No. 25

Bulletin et Mémoire de la Société Médicale des Hôpitaux de Paris, 1897, No. 16 and No. 17; Sur certaines Réactions Chromatiques du Sang dans le Diabète Sucré, Paris, 1897, pp. 44 to 81.

6 Lyon Médical, 1896, tome lxxxiii., p. 187.

Medicz, 1898 No. 10. Medicin, 1898, No. 28 .

Iedicin, 1898, No. 28. $27 \mathrm{th}, 1902$.

10 Philadelphia Medical Journal, 1998, No. 7
In each case two test-tubes of the usual size were half filled with the diabetic blood serum. To one test-tube ordinary German yeast was added, to the other no yeast was added. Both were kept in a warm place, side by side, for 48 hours, the mouth of each tube being plugged by cotton-wool. A the end of 48 hours the serum in the test-tube containing the yeast gave no reaction with methylene blue (according to the method above described), whilst 20 cubic millimetres of the serum in the tube which contained no yeast gave the reaction readily. The same results were obtained by the blood serum in all of the three cases of diabetes. The diabetic serum which had been submitted to the action of yeast and which did not decolourise methylene blue gave no reaction for sugar with Fehling's solution; whilst the diabetic serum to which no yeast had been added and which continued to give the reaction with methylen blue above described, gave a slight but distinct reaction for sugar with Febling's solution. The failure of the diabetic serum, after the action of yeast, to give the methylene-blue reaction was not due simply to the presence of the yeast. cells in the fluid, since diabetic serum when mixed with yeast and tested immediately gave the metbylene-blue reaction distinctly. Hence we may conclude that the diabetic serum loses its power of giving the methylene-blue reaction, owing to the fermenting action of the yeast fungus, which in the course of 27 or 48 hours destroys some substance in the serum.

3. After the proteids of diabatic blood or serum have been separated, by boiling with crystalline sulphate of soda and filtering, the filtrate-gives the methylene-blue reaction. A number of observations were made on the blood obtained post mortem from the internal jugular vein in a case of diabetes. In each examination an ounce or more of the blood or serum was mixed with an equal quantity of crystalline sulphate of soda and the mixture was boiled until the froth above the clot became white and all red specks disappeared. In every examination 20 cubic millimetres the clear filtrate gave the methylene-blue reaction abore described. When non-diabetic blood was treated with sodium sulphate in the same way the filtrate failed to give the methylene-blue reaction.

4. After the separation of the proteids of diabetic blood the power of giving the methylene-blue reaction is destroyed by the action of yeast. In another experiment, two testtubes were half filled with the clear filtrate, obtained after separating the proteids of diabetic blood by boiling with sodium sulphate, as just described. To the fluid in one testtube a little German yeast was added, while to that in the other tube no yeast was added. The mouth of each tube was plugged with cotton-wool and the tubes were kept in a warm place for 48 hours: Then the fluid in each tube was examined for the methylene-blue reaction abore described. 20 cubic millimetres of the fluid from the testtube of filtrate to which yeast had been added gave no reaction ; 20 cubic millimetres of the fluid from the test-tube to which no yeast had been added gave the reaction mark edly. The fluid in the test-tube to which yeast had been added gave no reaction for sugar either with Fehling's solu tion or phenyl-hydrazin, whilst the fluid in the other test tube, to which no yeast had been added, gave a reaction for sugar both with Fehling's solution and phenyl-hydrazin

5. It is well known that glucose bas the power of reducing a warm alkaline solution of methylene blue. 20 cubic milli metres of a watery solution of glucose (5 in 1000) gave distinct reaction with the methylene-blue test; but 20 cubic millimetres of a 2.5 in 1000 solution did not. When 20 cubic millimetres of the 2.5 in 1000 solution of glucose were added to 20 cubic millimetres of normal blood, the mixture decolourised the alkaline methylene blue like diabetic blood but 20 cubic millimetres of the blood alone, or of the 2.5 in 1000 glucose solution alone, failed to give the metbylene-blue reaction.

6. Though non-diabetic blood does not give the methyleneblue reaction in the proportions stated at the commencement of this article, it has nevertheless some reducing action in larger quantities. In performing the metbylene-blue blood test it is always necessary to measure accurately the quantity of blood employed ( 20 cubic millimetres), since the diabetic reaction depends on the greater reducing power of the diabetic blood. As already stated, I have never obtained the reaction when 20 cubic millimetres of blood were employed. in any condition except diabetes mellitus. But with norms blood a reaction may be obtained when 60 cubic milli metres of blood are employed in performing the test; also 
60 cubic millimetres of normal blood serum decolourise the methylene-blue solution. ( 20 cubic millimetres of serum have no action, just as in the case of 20 cubic millimetres of blood.) Hence there is also some substance in normal blood that has a reducing action when a sufficient quantity of blood is employed. This substance is in solution in the serum. But it is not simply the minute quantity of glucose, of normal or non-diabetic blood, since this reducing power is not destroyed by the action of yeast. Thus, two test-tubes of ordinary size were half filled with blood obtained post mortem from a case of aneurysm. To one test-tube yeast was added; to the other no yeast was added. Both were kept in a warm place for 48 hours. At the end of that time 60 cubic millimetres of blood from each tube reduced the methylene-blue solution readily. Hence there is a substance in non-diabetic blood, beside the minute quantity of sugar, which has some slight reducing actiop on methylene blue.

7. It is interesting to note that 20 cubic millimetres of diabetic urine gave the methylene-blue reaction markedly, whilst 20 cubic millimetres of the same diabetic urine in which the sugar had been decomposed by the action of yeast no longer gave the methylene-blue reaction; also 20 cubic millimetres of normal urine did not give the methyleneblue reaction.

Briefly summarised the results of the observations recorded may be stated as follows. The methylene-blue reaction, carried out with the proportions of fluid stated at the commencement of this article, may be obtained with a solution of glucose ; it is obtained with diabetic urine, with diabetic blood, with diabetic blood serum, and with the filtrate from diabetic blood when the proteids have been separated by boiling with crystalline sodium sulphate. All of these fluids after the action of yeast fail to give the reaction. As alresdy mentioned, when a dilute solution of glucose is added to normal blood the methylene-blue reaction is obtained. All these facts indicate that the methylene-blue reaction given by diabetic blood is due to the excess of glucose which it contains.

Clinical and Pathological Valte of the Reaction.

The methylene-blue reaction of diabetic blood is exceedingly delicate and may be obtained even when the urine contains only a very small quantity of sugar. Usually there is no difficulty, however, in diagnosing diabetes mellitus clinically. The examination of the urine is generally suffcient. The methylene-blue reaction of the blood is present in diabetic coma, and in this condition if the urine could not be obtained for examination (i.e., if the bladder should be empty) the blood reaction would be diagnostic. $R$. Müller ${ }^{11}$ has recorded a case of diabetic coma in which the diagnosis was definitely made by the blood reaction which I bave described, the bladder being empty and no urine being obtainable.

In the post-mortem appearances of persons dying from diabetes there is nothing characteristic. In the case of an individual dying from diabetic coma, if no history of the diabetic symptoms before the onset of coma could be obtained and if no urine could be found in the bladder nor any obtained which had been passed before death, a pathologist would not be able to diagnose the disease from the post-mortem appearances. Such cases, no doubt, have sometimes remained unrecognised in the past, and probably some of the obscure cases in which post-mortem examination made for the coroner has failed to reveal a satisfactory cause of death have been due to diabetic coma. The methyleneblue blood reaction in such cases would be diagnostic.

In five cases of diabetes mellitus I have removed blood from the internal jugular vein post mortem, and in every case 20 cabic millimetres of the blood gave the methyleneblue reaction markedly. Further, it is an interesting practical point that the reaction is obtained many hours after death. Thus in a case of diabetic coma in which the post-mortem examination was made 16 hours after death three ounces of the blood were placed in a bottle. Three days later the methylene-blue reaction was obtained markedly. In another case, blood removed from the internal izgular vein 10 hours after death gave the methylene-blue reaction after it had been kept in a bottle for a week. The reaction of course, is obtained early as well as later. I obtained it in one case in the blood taken from the internal ugular vein three hours after death. I have examined the clood taken post mortem from the internal jugular vein of 20

11 Xunchener Medicinische Wochenschrift, 1897, No. 25. individuals dying from various other diseases but have never obtained the reaction.

Hence this reaction may be of practical diagnostic value pathologically and medico-legally, in certain cases. I think it is advisable, when the blood is examined post mortern, to always take it from the internal jugular vein. Blood from this vein is not liable to be contaminated by other fluids during the necropsy. It is possible, also, that this delicate reaction may be made the basis of an easy method of estimating the amount of sugar in the blood. Two methods have already been worked out by Lyonnet and Le Goff, but it remains for future observations to show whether these methods are more delicate and reliable than those commonly employed.

Manchester.

\section{THE ETIOLOGY OF SCURVY.}

\section{BY W. E. HOME, B.Sc., M.D. Edin.,} STAFF SURGEON, RN.

I SHOULD like to offer some remarks on the very interesting paper of Mr. F. G. Jackson and Dr. V. Harley on Scurvy which appeared in THE LANCET of April 28th and to submit a suggestion as to the etiology of this important disease which has become so rare that $\mathbf{I}$ cannot be quite certain that $I$ have ever seen a case. The orthodox view is that it occurs in people who live on a diet deprived of green vegetables or potatoes, its onset being accelerated by preceding hardships, while it is prevented by a daily ration of lime-juice and cured by lime-juice or fresh vegetables. Torup and Nansen suggested that it might arise from ptomaine posioning, which was noted in THE LANCET of Feb. 13th, 1897, as a new departure, and this suggestion Mr. Jackson and Dr. Harley endeavour to support by their research reported in THE LANCET of April 28th. They fed six monkeys on sound meat and 13 on tainted meat and in these last found evidences of scurvy-namely, as they say, bloody mucus in the stools, spongy gums, and characteristic anæmia; also there were post-mortem appearances of irritation in the mouth (spongy gums-that is to say, I suppose, inflammation of the gums-going on to ulceration) and irritation of the large intestine. They consider their observations support the theory that "scurvy is essentially due to poisoning by the ptomaines of tainted animal food." In their experiments, however, they did not take care to administer ptomaines only, but as the "sour-smelling meat" on which the second lot of monkeys were fed had not been sterilised, only as they say "gentiy heated," the monkeys got not only ptomaines but also the living bacteria which produced the ptomaines. What is there, then, in these experiments to prevent us from believing that the bacteria of putrefaction were taken alive into the mouths of the monkeys, there infecting the sordes round the teeth and setting up gingivitis, going on to ulceration, infecting also the gastro-intestinal canal later, these parasitic infections setting up the anæmia on which all the other symptoms of scurvy depend? Anæmia is generally the effect of the struggle of the organism against some infection. How pale a person becomes after suffering for a couple of days from a large boil, and think of Hunter's most valuable researches into the etiology of pernicious anæmia and Sir Andrew Clark's explanation of chlorosis. Clearly the anæmia will develop all the faster if the victims are, as so often. happens in epidemics of scurvy, on short rations, particularly if they are taking in fresh doses of the poison with each scanty meal, and they probably were taking in fresh doses with each mouthful, for Lind describes their beef as rotten, their pork as rancid, their flour as mouldy, and their water as unwholesome. And Gillespie describes the beef the men had to eat in the Persian Gulf as so rotten that it could not properly be boiled. They tied it up with strings but it fell out of them, wherefore their Arab pilot greatly pitied them and preferred rather to go ashore where there was a great epidemic of plague than to remain in their ship where he could get no other food.

It is curious that in the same number of THE LANCET (April 28th) there should be an account of a case of pernicious anæmia associated with, and in the opinion of Dr. W. Elder mainly due to, neglected state of the teeth, cured by buccal antisepsis, anti-streptococcic serum (the 